\title{
Carlos Mata Induráin (ed.), "A dos luces, a dos visos». Calderón y el género sacramental en el Siglo de Oro, Kassel, Reichenberger, 2020, 284 pp. ISBN: 978-3-967280-01-2
}

\section{Iñaki Pérez Ibáñez}

University of Rhode Island ESTADOS UNIDOS

ignacioperez@uri.edu

[Hipogrifo, (issn: 2328-1308), 9.2, 2021, pp. 1141-1144]

Recibido: 20-08-2021 / Aceptado: 10-09-2021

DOI: http://dx.doi.org/10.13035/H.2021.09.02.79

Desde que en 1992 el Grupo de investigación Siglo de Oro (GRISO) comenzó a editar la totalidad de los autos sacramentales calderonianos, el interés que este género ha despertado tanto en la crítica como en el público no ha hecho sino ir en aumento. Su labor no solo ha puesto a disposición del lector ediciones de calidad, con textos fiables precedidos de acertados estudios críticos, sino también herramientas para la edición de textos (como el Diccionario de los autos sacramentales), documentos y memorias de apariencias, y estudios (ya sean colectivos o individuales) que se centran en aspectos concretos de la obra calderoniana. El volumen que voy a reseñar es el último número (96) de esta colección. El editor no es otro sino Carlos Mata Induráin, quien anteriormente ha participado en la edición de tres autos en esta serie: El año santo en Madrid, El jardín de Falerina y La siembra del Señor.

En esta obra colectiva se recogen 14 estudios firmados por algunos de los mayores calderonistas en activo. Una versión preliminar de la mayor parte de estos trabajos se leyó en el Congreso Internacional «El auto sacramental en el Siglo de Oro. El maestro Calderón» (Pamplona, abril de 2018). Los trabajos aquí compilados siguen distintas metodologías, se centran en obras de diversos autores y épocas, y su temática es amplia. Dicha variedad no hace sino enriquecer el conjunto. De estos trabajos, nueve se dedican a los autos de Calderón y su recepción, mientras que los cinco restantes se dedican a obras de Lope, Tirso, Claramonte, o anónimas 
como el Auto de la destrucción de Jerusalén. Por cuestión de espacio, no vamos a pararnos en todos y cada uno de los capítulos incluidos en el volumen. No se trata de que los trabajos que no mencionamos carezcan de interés, sino de una necesidad de concisión.

Dominique Courcelles, quien firma el primer estudio recogido en el libro («Teología y metafísica del auto sacramental: algunas interpretaciones francesas del teatro del mundo en contrapunto del maestro Calderón», pp. 9-18), compara el desarrollo del género sacramental en España y Francia. Su trabajo se basa en una serie de calas en la producción de tres autores franceses donde aparece el tópico del Theatrum Mundi: Ronsard, Boaistuau, y Montaigne. Su conclusión es que, mientras que en la península se da un desarrollo pleno de este, en Francia no se alcanzan la misma profundidad teológica y «no se pasa el horizonte trágico de las miserias humanas del Teatro del Mundo» (p. 17). Es sin duda un primer acercamiento interesante al tema, pero resulta obvio que este no se agota y que es necesario una continuación en profundidad donde explorar con mayor detenimiento algunos de sus postulados.

Solo se puede poner una pega al trabajo de Juan Manuel Escudero: la ambición de su título ( «El magisterio de la escritura calderoniana en sus autos sacramentales autógrafos», pp. 19-39) pues realmente se centra solo en El laberinto del mundo. Examina las correcciones y alteraciones que Calderón hizo al autógrafo del auto que se conserva en la Biblioteca Histórica del Ayuntamiento de Madrid. El investigador analiza en detalle tres capas de pulimiento textual y menciona que una cuarta capa aparece de forma excepcional (por ejemplo, cuando se añade una tira de papel en el folio 3r para copiar en limpio un texto que había modificado de forma sustancial eliminando versos y añadiendo otros en el margen derecho, y sobre el que introduce pequeñas modificaciones). Lo interesante no es la descripción de las variantes en los diferentes estados de revisión, sino la explicación de la causa subyacente que llevó al dramaturgo a revisar su texto. Escudero hace un laudable esfuerzo por desentrañar las razones que pudieron motivar a Calderón y presenta argumentos plausibles y convincentes. Resulta muy interesante leer este trabajo en paralelo al que dedica al mismo texto Santiago Fernández Mosquera y que le sigue inmediatamente en el volumen («Unas enmiendas para la prosperidad: El laberinto del mundo y la reescritura de un género», pp. 41-52). También el investigador gallego fija su atención en las variantes que presentan los diferentes testimonios del auto y llega a la conclusión de que el texto que en la mayoría de los casos se ha transmitido representa el que se escribió para su primera representación en la que participó Cosme Pérez, el famoso Juan Rana, y no el que Calderón preparó para que viese las prensas, donde los versos circunstanciales y los chistes fáciles que estaban destinados al lucimiento del actor se suprimieron.

Iglesias Feijoo firma un excelente capítulo titulado «Calderón y el metateatro» (pp. 103-126). Comienza analizando las primeras conceptualizaciones de la metateatralidad y juzga que el acierto de Lionel Abel está en «enfocar el objetivo sobre cierto tipo de obras que al menos desde el siglo XVI no se adecúan al simple propósito de ofrecer una 'imagen de vida', un 'reflejo' de la realidad» (p. 104). Las 
obras metateatrales subrayan el carácter ficticio de las acciones que se presentan ante el espectador y hacen hincapié en su teatralidad (p. 105). Cubero («En torno a La entretenida de Cervantes. El teatro dentro del teatro y el teatro sobre el teatro», 1997, p. 62) consideraba que la forma metateatral más pura es la representación en escena de una obra dentro de una obra, donde un grupo de personajes se convierte en actores y otro en espectadores intrínsecos. No es esta la opinión de Iglesias Feijoo para quien el aspecto más interesante de este fenómeno no es la representación de una obra dentro de una obra o «fingir una realidad fabricada como si fuera "verdad"» (p. 107) sino las obras que subrayan su propia teatralidad a través de un personaje que se convierte en autor o cuando menos director de escena, pues es él quien crea la intriga o trama en la que los demás personajes serán representantes inconscientes. Por lo tanto «lo que se ve y oye es una construcción, algo fingido por alguien [un personaje] que lo planea y a cuyo despliegue asistimos hasta el desenlace. No se elimina la ficción: se la potencia al resaltar que lo es» (p. 107). Subraya este autor el carácter eminentemente metateatral de los autos, al tratarse de obras «inverosímiles y antirrealistas» (p. 107) donde a menudo aparece un personaje-demiurgo que planea la acción. En muchos de los autos calderonianos dicho personaje se corresponde con el Demonio (quien planifica la acción para lograr la condenación del hombre, si bien el público ya sabía que iba a ser testigo de su fracaso al final de la obra). Es en este grupo de obras en el que se centra el estudio de este crítico.

Carlos Mata firma el trabajo más extenso del volumen titulado «Algo más sobre la construcción alegórica del auto sacramental de La Araucana, atribuido tradicionalmente a Lope de Vega (y más recientemente a Claramonte)» (pp. 141-178). En su detallado estudio, se recogen todos los indicios y pruebas que han llevado a defender una posible autoría de Claramonte, llegando a la conclusión de que «la cuestión con solo estos datos, parece irresoluble». No acabo de compartir esta opinión, ya que los argumentos en favor de la autoría de Claramonte que presenta Rodrigo Faúndez Carreño en los trabajos que dedicó a este auto en 2017 y 2018 (en lo que se me alcanza los más detallados y los últimos que aportan nueva documentación al respecto y que incluyen la edición más fiable del texto) me parecen convincentes. A este respecto resulta curioso que el trabajo de Delia Gavela García dedicado al auto El dote del Rosario de Claramonte y recogido en este volumen («El dote del rosario de Claramonte, ¿un auto sacramental al uso?», pp. 53-68), solo le atribuya dos autos, uno al que dedica su estudio y El horno de Constantinopla, sin incluir ninguna mención a la posible autoría de La Araucana. Por su parte, Nogués Bruno en su intento de clasificación de los autos lopianos («Clasificación de los autos sacramentales de Lope de Vega», pp. 179-192) incluye La Araucana como una de las piezas de Lope de Vega, si bien, en nota a pie señala rápidamente que su autoría ha sido atribuida a Claramonte en 2018. Volviendo al trabajo de Carlos Mata, recoge este estudioso un detallado apartado sobre la opinión que el auto ha despertado entre la crítica. Esta se ha movido entre extremos: mientras unos la juzgan una aberración (Menéndez Pelayo, Wardropper, Dixon o Pérez-Amador Adam, entre otros), hay quienes la consideran una obra de gran modernidad, donde se propone un sincretismo entre culturas (sirvan de ejemplo Ruiz Ramón, Mónica Es- 
cudero, Patricio Lerzundi o Moisés R. Castillo). Dicho sincretismo, se basaría en la asimilación de «la supuesta antropofagia de los indígenas araucanos con el hecho de comer el Cuerpo y la Sangre de Cristo como alimento espiritual del cristiano» (pp. 169-170). Dicha identificación aparece también en varios autos calderonianos donde se compara a los devotos con los pueblos caribes por este mismo motivo (por ejemplo en El cordero de Isaías, vv. 545-546).

Regresemos rápidamente al trabajo de Nogués Bruno. Señala esta investigadora y analiza en detalle uno de los grandes problemas de quien intenta acercarse a los autos de Lope de Vega: el corpus todavía es muy discutido, al menos ocho de la cuarentena de autos que se le atribuyen tradicionalmente tienen una autoría dudosa en mayor o menor grado. No se menciona que las particularidades de estas piezas, tan diferentes de las calderonianas, llevaron a Menéndez Pelayo a negarles el carácter de autos sacramentales y a Aicardo a distinguir entre «autos no eucarísticos por su materia» y «eucarísticos por acomodación». La propia Nogués Bruno en su tesis doctoral de 2011 propuso referirse a ellos como «autos de circunstancias», denominación de la que Amparo Izquierdo Domingo se hizo eco en su libro Los autos sacramentales de Lope de Vega. Clasificación e interpretación (Editorial Academia del Hispanismo, 2013). En el presente trabajo, se toma como punto de partida los conceptos de asunto y argumento, lo que le lleva a esta investigadora a distinguir entre siete grupos: 1) Autos filosóficos y teológicos; 2) Autos inspirados en el Antiguo Testamento; 3) Autos inspirados en parábolas y relatos evangélicos; 4) Autos de circunstancias; 5) Autos históricos y legendarios; 6) Autos navideños; 7) Autos marianos. Este esquema clasificatorio me resulta claro y práctico.

El enfoque que tiene el trabajo de Alejandro González Puche es muy diferente del que siguen el resto de los capítulos («La percepción popular de El gran teatro del mundo», pp. 89-102). Desde su condición de director de escena, este reflexiona sobre la aceptación popular que tuvo la versión del auto El gran teatro del mundo que llevó a las tablas el Laboratorio Escénico Univalle y que conoció casi un centenar de representaciones en escenarios de Estados Unidos, Colombia y México. Resulta muy interesante la descripción de la relación entre lo que la compañía había planeado y la percepción que de la obra tuvo el público. Así mientras que su intención era llevar a cabo «un ejercicio de adaptación a la modernidad colombiana» (94) donde el autor se convierte en un director cultural patrocinado por una ONG para cultivar los talentos e integrar socialmente a los habitantes de un barrio de chabolas, el público colombiano entendía el espectáculo como un reflejo de sus raíces españolas.

En definitiva, nos encontramos ante una interesante colección de pequeñas calas en autos sacramentales de diferentes autores. No es su intención hacer un estudio exhaustivo del auto sacramental ni del tratamiento que en él se hace de algún tema en concreto, sino dar un paso más que nos acerque a una mejor comprensión del género sacramental en general y de los autos calderonianos en particular, cosa que sin duda el presente volumen consigue. 